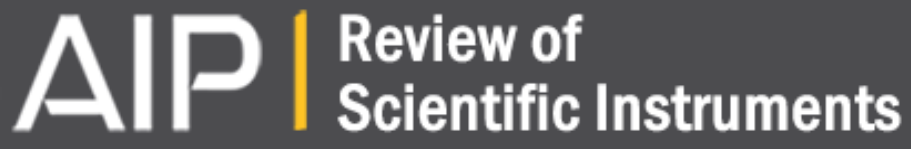

A microfluidic flow-cell for the study of the ultrafast dynamics of biological systems

Adrien Chauvet, Tania Tibiletti, Stefano Caffarri, and Majed Chergui

Citation: Review of Scientific Instruments 85, 103118 (2014); doi: 10.1063/1.4899120

View online: http://dx.doi.org/10.1063/1.4899120

View Table of Contents: http://scitation.aip.org/content/aip/journal/rsi/85/10?ver=pdfcov

Published by the AIP Publishing

Articles you may be interested in

A novel microfluidic flow focusing method

Biomicrofluidics 8, 054120 (2014); 10.1063/1.4899807

Vascular smooth muscle cell culture in microfluidic devices

Biomicrofluidics 8, 046504 (2014); 10.1063/1.4893914

Optimization of an electrokinetic mixer for microfluidic applications

Biomicrofluidics 6, 024123 (2012); 10.1063/1.4722000

Thiolene-based microfluidic flow cells for surface plasmon resonance imaging

Biomicrofluidics 5, 026501 (2011); 10.1063/1.3596395

An integrated microfluidic system for isolation, counting, and sorting of hematopoietic stem cells

Biomicrofluidics 4, 024112 (2010); 10.1063/1.3454767

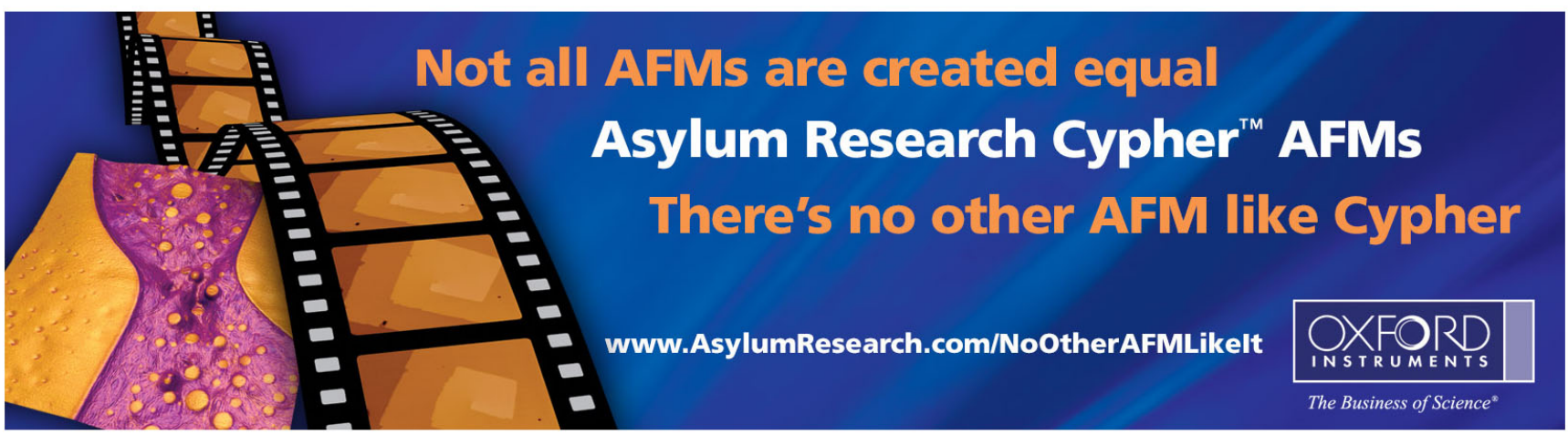




\title{
A microfluidic flow-cell for the study of the ultrafast dynamics of biological systems
}

\author{
Adrien Chauvet, ${ }^{1, a)}$ Tania Tibiletti, ${ }^{2}$ Stefano Caffarri, ${ }^{2}$ and Majed Chergui ${ }^{1}$ \\ ${ }^{1}$ Ecole Polytechnique Fédérale de Lausanne (EPFL), Laboratoire de Spectroscopie Ultrarapide, \\ ISIC, Faculté des Sciences de Base, Station 6, 1015 Lausanne, Switzerland \\ ${ }^{2}$ Aix Marseille Université, CNRS, CEA, UMR 7265 Biologie Végétale et Microbiologie Environnementales, \\ 13009 Marseille, France
}

(Received 21 July 2014; accepted 12 October 2014; published online 29 October 2014)

\begin{abstract}
The study of biochemical dynamics by ultrafast spectroscopic methods is often restricted by the limited amount of liquid sample available, while the high repetition rate of light sources can induce photodamage. In order to overcome these limitations, we designed a high flux, sub-ml, capillary flow-cell. While the $0.1 \mathrm{~mm}$ thin window of the $0.5 \mathrm{~mm}$ cross-section capillary ensures an optimal temporal resolution and a steady beam deviation, the cell-pump generates flows up to $\sim 0.35 \mathrm{ml} / \mathrm{s}$ that are suitable to pump laser repetition rates up to $\sim 14 \mathrm{kHz}$, assuming a focal spot-diameter of $100 \mu \mathrm{m}$. In addition, a decantation chamber efficiently removes bubbles and allows, via septum, for the addition of chemicals while preserving the closed atmosphere. The minimal useable amount of sample is 250 $\mu$ l. (C) 2014 AIP Publishing LLC. [http://dx.doi.org/10.1063/1.4899120]
\end{abstract}

\section{INTRODUCTION}

Optical and X-rays sources of ultrafast pulses are nowadays common analytical tools for the studying of chemical and biochemical liquid samples. Ultrafast optical and X-ray spectroscopies and X-ray diffraction are particularly suitable for the study of biological complexes as they allow monitoring the protein's nuclear responses and therefore identify those modes that are biologically relevant. ${ }^{1-4}$ In addition, the advent of in the IR, ${ }^{5}$ the visible, ${ }^{6-8}$ and the $\mathrm{UV}^{9,10}$ is opening new perspectives for the study of biochemical dynamics.

Due to the inherent $\sim \mathrm{kHz}$ repetition rate of ultrafast laser systems and their fluences, liquid samples have to be flowed in order to minimize unwanted effects such as photodamage, heating, multi-photon absorption, and saturation. So far, two solutions are commonly used: (a) The flow-cell, typically connected to a peristaltic pump that is used to circulate the sample solution through the cell. The advantage of the method is the stability to the cell, which consequently reduces the noise. It also allows for small path lengths and thin windows, down to $0.02 \mathrm{~mm}$, therefore reducing scattering of the excitation beam through the glass as well as increasing the time resolution due to limited group velocity dispersion. However, it typically requires large amounts of sample ( $\gg \mathrm{ml})$. (b) The spinning-cell, which consists of two circular glass plates that are spaced by the desirable optical path-length. ${ }^{11}$ While rotating, the sample either creates a rim at the edge of the cell, or at lower rotation speed, the solution remains at the bottom of the cell but is constantly mixed by friction with the glass. The advantage is that it typically requires minimal amounts of sample $(\sim 0.3 \mathrm{ml})$. However, because the rotation of the glass plate causes the excitation beam to sweep a large surface, the cleanness of the

\footnotetext{
a) Author to whom correspondence should be addressed. Electronic mail: adrien.chauvet@epfl.ch.
}

plates is directly related to the noise. It is consequently burdensome to clean, and because the cell consists of a moving glass plate at the focal point of the laser beam, the precision of the alignment is also crucial to minimize the noise. Furthermore, since the glass plates are typically few $\mathrm{cm}$ in diameter, the required minimal thickness of the glass lowers the time resolution.

In terms of purified biological proteins that are not commercially available, a volume of $\sim 0.3 \mathrm{ml}$ associated to a typical protein concentration of $100 \mu \mathrm{M}$ represents about a month-long of successive growth of the organisms and protein purification cycles. ${ }^{12,13}$ Consequently, the flow-cell is not an option. The spinning-cell is a better compromise but it is laborious to implement in order to reach comparable signalto-noise ratios.

With the current miniaturization of technology, different micro-pumping options are now commercially available such as micro-peristaltic and flow-through pumping. We found that the flow-through micro-pumps offer the best compromise in terms of required volume and generated flow rate.

In the case of low sample volumes, the implementation of a closed circuit raises concerns about bubbles that would notably increase the noise. We propose an alternative approach: a microfluidic flow-cell that retains the advantages of low sample volumes and of a steady cell, while providing an effective way to remove enclosed bubbles. This system is, to our knowledge, the easiest to implement, and it requires only sub-ml amounts of sample, while being suitable to excitation repetition rates up to $\sim 14 \mathrm{kHz}$. We demonstrate its use in the case of the photosynthetic Reaction Center (RC), Photosystem I (PSI), while monitoring the ultrafast charge separation mechanisms. Because of the high sensitivity to photo-accumulation, the distinct features of the PSI transient signal will serve as a confirmation for the flow-cell's effectiveness. 


\section{MATERIAL AND METHODS}

Growth condition: Synechocystis 6803 wild-type was cultivated at $30^{\circ} \mathrm{C}, 60 \mu \mathrm{mol}$ photons $\mathrm{m}^{-2} \mathrm{~s}^{-1}$, in BG-11 medium ${ }^{14}$ continuously bubbled with air or shaken at 100 rpm. Cultures were harvested at $\mathrm{OD}_{730}$ of 0.5-0.8.

Thylakoid purification and PSI trimer isolation: Cells were harvested by centrifugation $\left(10000 \mathrm{~g}, 10 \mathrm{~min}, 4^{\circ} \mathrm{C}\right)$, washed twice with $20 \mathrm{mM}$ 2-(N-morpholino)ethanesulfonic acid (MES) $\mathrm{pH} 7.0,10 \mathrm{mM} \mathrm{CaCl}, 10 \mathrm{mM} \mathrm{MgCl}_{2}$ and stored at $-80^{\circ} \mathrm{C}$ in the same buffer plus $1 \mathrm{mM}$ aminocaproic acid (ACA) and 20\% glycerol. Cells were broken with glass beads (BioSpec. Products) using a tissue homogenizer (MM300 Retsch). Complete ${ }^{\mathrm{TM}}$ Ethylenediaminetetraacetic acid (EDTA)-free protease inhibitor (Roche) was added to the suspension. Glass beads and unbroken cells were eliminated by centrifuging samples at $3000 \mathrm{~g}, 5 \mathrm{~min}, 4^{\circ} \mathrm{C}$. Membranes were precipitated at $30000 \mathrm{~g}, 30 \mathrm{~min}, 4^{\circ} \mathrm{C}$ and resuspended in $50 \mathrm{mM}$ Bis-Tris pH 7.0, $10 \mathrm{mM} \mathrm{MgCl} 2,1 \mathrm{mM}$ ACA, $20 \%$ glycerol. To remove phycobilisomes, membranes were precipitated again at $30000 \mathrm{~g}, 30 \mathrm{~min}, 4^{\circ} \mathrm{C}$ and resuspended in $25 \mathrm{mM}$ Bis-Tris pH 7.0, $10 \mathrm{mM} \mathrm{MgCl}{ }_{2}, 1 \mathrm{mM}$ ACA, $20 \%$ glycerol and stored at $-80^{\circ} \mathrm{C}$ (if necessary). Chlorophyll content was measured in $80 \%$ acetone according to Ref. 15 . Thylakoids at $1 \mathrm{mg} / \mathrm{ml}$ chlorophyll concentration were solubilized using $1 \% \mathrm{n}$-Dodecyl $\beta$-D-maltoside ( $\beta$-DM) final concentration under constant stirring on ice for $10 \mathrm{~min}$. Unsolubilized membranes were removed by centrifugation $(21000 \times \mathrm{g}, 30$ min, $4{ }^{\circ} \mathrm{C}$ ). The solubilized sample was fractionated by ultracentrifugation on a sucrose gradient in a SW41 rotor for $17 \mathrm{~h}, 41000 \mathrm{rpm}, 4^{\circ} \mathrm{C}$. Gradients were formed directly in the tube by freezing and thawing a solution of $0.65 \mathrm{M} \mathrm{su}-$ crose, $25 \mathrm{mM}$ Bis-Tris pH 7.0, $1 \mathrm{mM}$ ACA, $0.01 \% \beta$-DM, and loaded with $100 \mu \mathrm{g}$ of membranes (expressed as initial chlorophyll) per tube. Sodium L-ascorbate $(20 \mathrm{mM})$ and $\mathrm{N}$-methylphenazonium methyl sulfate (PMS, $20 \mu \mathrm{M}$ ) were added to the sample to ensure reduction of $\mathrm{P}_{700}{ }^{+}{ }^{16}$

Optical transient spectroscopy: The laser system is a 1 $\mathrm{kHz}$ regenerative amplifier providing $\sim 40$ fs pulses focused onto $\sim 150 \mu \mathrm{m}$ spot size as described in Ref. 17. The sample is housed in the subsequently described flow-cell. The fluence was kept low to an average of 0.5 excitations per PSI, therefore avoiding any annihilation effects.

Data analysis: The data are globally fitted as a sum of multiple exponential decays using a singular value decomposition method as explained in Ref. 18. The computation of the amplitude of each exponential decay in function of the wavelength results in the Decay Associated Spectra (DAS).

\section{THE MICROFLUIDIC FLOW-CELL}

The flow cell is composed of three elements, as illustrated in Figure 1(a), that are connected via flexible tubing of $1 \mathrm{~mm}$ diameter:

The bubble chamber: It is a home-made polymer cylindrical chamber as shown in Figures 1(a) and 1(b). The 0.5 $\mathrm{mm}$ diameter inlet and outlet are at the bottom of the cuvette to minimize turbulences that are created at high flow rates. In an upward position, the cuvette by itself requires a min-
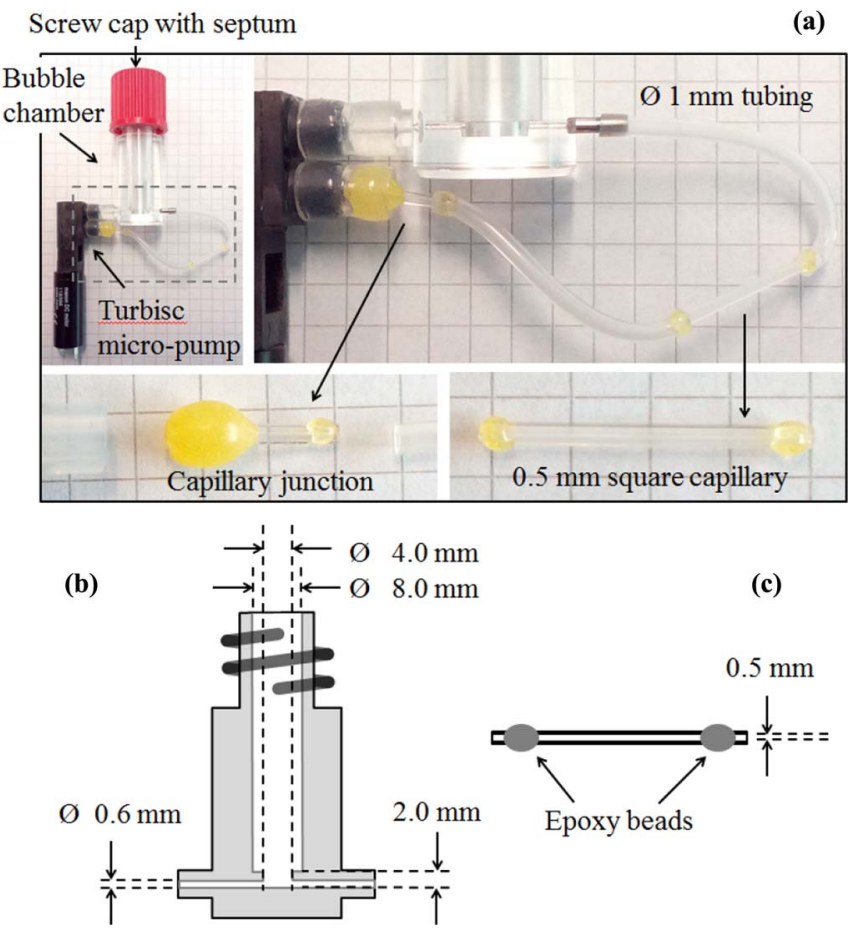

FIG. 1. (a) Overall view of the assembled system, with zoom on the capillary junctions. (b) Side view of the bubble chamber and (c) of the capillary window.

imal amount of $\sim 50 \mu \mathrm{l}$ of liquid sample in order to have a continuous flow between the inlet and outlet. The excess sample fills up the cuvette and allows the bubbles present in solution to rise to the surface. The bubbles are naturally trapped by the cuvette while passing through, at low flowspeed. At high flow-speed however, larger sample volume are required in order to avoid the suction of air due to the liquid's turbulences. The top of the chamber is threaded to fit a standard septum screw cap. This allows for the addition of chemicals to the enclosed solution while keeping the confined atmosphere protected and avoiding evaporation of the solvents.

The capillary window: It is made of a square quartz silica capillary bought from Composite Metal Services Ltd (CMS). It has a path-length of $0.5 \mathrm{~mm}$ with $0.1 \mathrm{~mm}$ thin walls. Segments of $\sim 2 \mathrm{~cm}$ long are cut and epoxy is added at the extremities (Figures 1(a) and 1(c)). The epoxy beads allows for a hermetic junction between the square capillary and the flexible tubing. Note that a shorter segment of capillary with a larger epoxy bead is used to connect the $1 \mathrm{~mm}$ diameter flexible tubing to the $2 \mathrm{~mm}$ diameter outlet of the pump (Figure 1(a)). Because of the simplicity of its fabrication and mounting, the capillary is easily replaceable if needed. It is fixed at the center of a rotation mount that allows for fine adjustment of the angle between the incident beam and the window.

The turbisc pump: It is a design from the Swiss Center for Electronics and Microtechnology (CSEM). ${ }^{19}$ In short, the flow is created by direct friction between a grooved shaft and the liquid. The inner volume of liquid that the pump contains is about $100 \mu \mathrm{l}$ only. Because the housing and the seal are respectively made out of Polyetherimide and of Polyetheretherketone, the pump is relatively resistant to chemicals. 


\section{FLOW-CELL PERFORMANCES}

When the pump, the chamber, and the capillary are connected, the minimal volume of sample needed for good working conditions is about $250 \mu \mathrm{l}$ only. This configuration includes a total tubing ( $1 \mathrm{~mm}$ inner diameter) length of $\sim 6 \mathrm{~cm}$ and a sufficient amount of sample in the cuvette to avoid the suction of bubbles due to turbulences with a minimal flow of $\sim 0.1 \mathrm{ml} / \mathrm{s}$. The flow is proportional to the voltage applied to the pump and under the same configuration the maximum flow rate was measured to be $\sim 0.36 \mathrm{ml} / \mathrm{s}$. While assuming a typical laser focus diameter of $100 \mu \mathrm{m}$ within the $0.5 \times$ $0.5 \mathrm{~mm}^{2}$ square capillary, the flow, if uniform, is theoretically sufficient to refresh the sample within the laser focus for each laser shot at a excitation rate of up to $\sim 14 \mathrm{kHz}$. In practice, it is to remember that the flow is impeded on the edges of the capillary and consequently the value of $14 \mathrm{kHz}$ has to be taken as an upper limit only. Alternatively, if the pump is connected to a standard flow-cell of section $0.2 \times 0.8 \mathrm{~mm}^{2}$ via $2 \mathrm{~mm}$ inner diameter tubing and overloaded with $9.4 \mathrm{~V}(6 \mathrm{~V} \mathrm{recom-}$ mended), the pump is able to sustain a flow up to $0.98 \mathrm{ml} / \mathrm{s}$. Taking into account that the inner volume of the pump is only about $100 \mu \mathrm{l}$, it therefore represents one of the best (if not the actual best) compromise between flow-rate and required volume.

\section{TEST MEASUREMENTS}

We choose the well-known PSI RC as model system to test the cell, because of its high sensitivity to excitation build-up. After photoexcitation, the protein complexes undergo charge separation with a near unity quantum yield..$^{20}$ This charge separation is associated to a distinct transient signal from the special pair $\left(\mathrm{P}_{700}\right)$ in the $\mathrm{Q}_{\mathrm{y}}$ region of $\mathrm{Chl}$ $a(\sim 700 \mathrm{~nm}) .{ }^{21}$ Until charge recombination occurs, in about $2.5 \mathrm{~ms}$ in the presence of PMS, ${ }^{22}$ the special pair remains oxidized $\left(\mathrm{P}_{700}{ }^{+}\right)$and any extra photon absorbed is efficiently quenched, ${ }^{21}$ i.e., the protein complex is said to be "closed." Consequently, if the sample flow is insufficient, the quick accumulation of closed RCs will result in the loss of transient signature from $\mathrm{P}_{700}{ }^{+}$. As shown in Figures 2(a1) and 2(a2), indeed when the cell-pump is "off" the ns-DAS component lacks the $\mathrm{P}_{700}{ }^{+}$signal signature. The broad bleach, which mirrors the overall $\mathrm{Chl} a \mathrm{Q}_{\mathrm{y}}$ absorption band, corresponds to the decay of the excited Chl $a$ population, i.e., to the quenching of the excitation, confirming that all complexes are closed within the laser beam path. On the other hand, when the cell is driven with a minimal voltage, a flow of $\sim 0.07 \mathrm{ml} / \mathrm{s}$ is sufficient to monitor the transient signal expected for $\mathrm{P}_{700}{ }^{+}$as represented in Figure 2 and more specifically by the ns DAS component in Figure 2. Moreover, in this figure, the $\sim 2: 1$ ratio between the maximum amplitudes of the 30 ps DAS, representing the trapping of the excitation toward the special pair, ${ }^{16,21,23,24}$ and the ns DAS component, representing the oxidized special pair, ${ }^{21}$ shows that the amount of chargeseparated states was optimum with respect to the number of photon absorbed. ${ }^{16}$ In other words, with a minimal sample volume and driven at the lowest voltage, the flow is sufficient to effectively refresh the sample for each laser shot with a
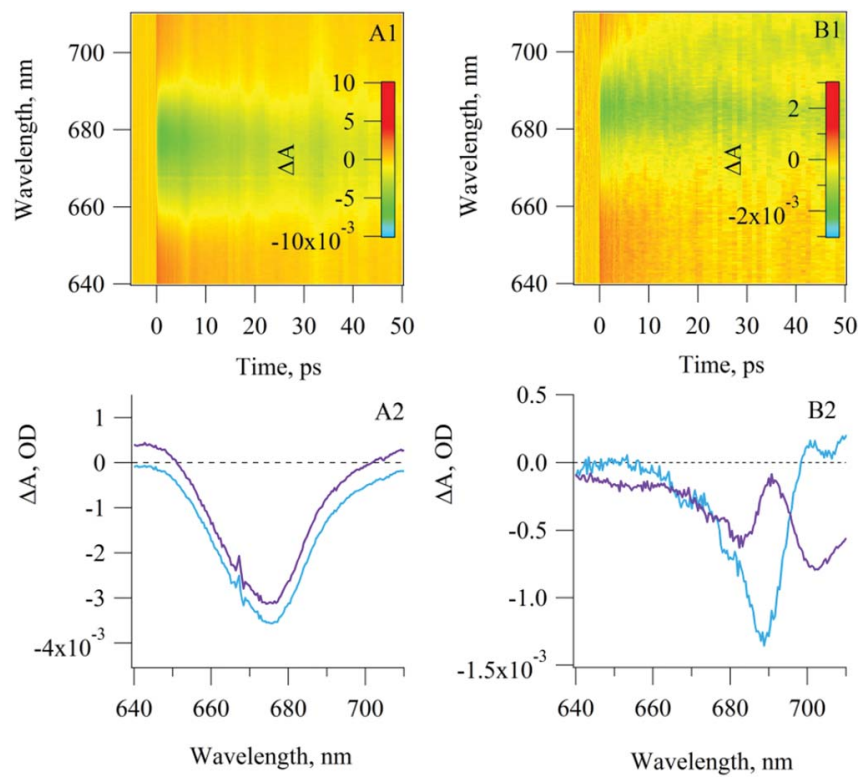

FIG. 2. Transient signal in the Chl $a \mathrm{Q}_{\mathrm{y}}$ band spectral region of the PSI RCs excited using $480 \mathrm{~nm}$ pulses at $1 \mathrm{kHz}$ repetition rate when the cell pump is off (a1) and on (b1). In the latter case, a minimal flow of $\sim 0.07 \mathrm{ml} / \mathrm{s}$ was used. DAS components of the $30 \mathrm{ps}$ (blue) and $>>1 \mathrm{~ns}$ (purple) when the cell pump is off (a2) and on (b2).

$1 \mathrm{kHz}$ repetition rate and a relatively large focal spot size, i.e., no accumulation effects were monitored over the few hours of the experiment. The sample integrity was controlled by subsequent absorption spectra taken directly through the capillary via the probe beam (not shown). Since the spectra before and after the experiment were virtually identical, we infer that the protein's structure of this PSI trimeric super complex $(\sim 210 \AA \text { in diameter })^{25}$ was preserved by passing through the pump. The flow-through pump is consequently safe for applications where the sample size is comparable or smaller to that of the trimeric PSI. Note that we demonstrated the flow-cell's effectiveness using a typical $1 \mathrm{kHz}$ laser system in the visible, however such a flow-cell is equally suitable for time resolved X-ray measurements ${ }^{26}$ of solutions with the appropriate capillary material, i.e., mylar instead of quartz.

\section{CONCLUSION}

We implemented a microfluidic flow-cell that requires a minimal amount of sample ( $\sim 250 \mu \mathrm{l})$, while the pump generates sufficient flow for the common use of high repetition rate systems; up to $\sim 14 \mathrm{kHz}$ for a focal spot-size of the excitation beam of $100 \mu \mathrm{m}$. Contrary to the spinning-cell, we have a steady $0.1 \mathrm{~mm}$ thin window capillary. The closed circuit includes a decantation chamber that efficiently ejects bubbles that are enclosed during assembly. The three components are connected via flexible tubing that effectively eases both, the installation and the alignment.

\section{ACKNOWLEDGMENTS}

This project has been funded by the Swiss NSF via the NCCR:MUST and by the FP7 Marie Curie COFUND. We 
thank particularly Gil Corbaz, technician at ISIC, EPFL, for the precision machining and Noa Schmid, project manager at CSEM, for valuable discussions.

${ }^{1} \mathrm{M}$. Chergui, in Comprehensive Biophysics, edited by E. H. Egelman (Academic Press, Oxford, 2012), vol. 1, pp. 398-424.

${ }^{2}$ A. Rosspeintner, B. Lang, and E. Vauthey, Annu. Rev. Phys. Chem. 64, 247-271 (2013).

${ }^{3}$ R. Berera, R. van Grondelle, and J. T. M. Kennis, Photosynth. Res. 101, 105-118 (2009).

${ }^{4} \mathrm{M}$. Chergui, in In-situ Materials Characterization: Across Spatial and Temporal Scales, edited by A. Ziegler, H. Graafsma, X. F. Zhang, and J. W. M. Frenken (Springer, 2014).

${ }^{5}$ P. Hamm and M. Zanni, Conceps and Methods of $2 D$ Infrared Spectroscopy (Cambridge University Press, 2011).

${ }^{6}$ T. Brixner, T. Manal, I. V. Stiopkin, and G. R. Fleming, J. Chem. Phys. 121(9), 4221-4236 (2004)

${ }^{7}$ E. E. Ostroumov, R. M. Mulvaney, R. J. Cogdell, and G. D. Scholes, Science 340, 52-56 (2013).

${ }^{8}$ H. Zheng, J. R. Caram, P. D. Dahlberg, B. S. Rolczynski, S. Viswanathan, D. S. Dolzhnikov, A. Khadivi, D. V. Talapin, and G. S. Engel, Appl. Opt. 53(9), 1909-1917 (2014).

${ }^{9}$ C. Consani, G. Auböck, F. van Mourik, and M. Chergui, Science 339, 1586-1589 (2013).

${ }^{10}$ B. A. West and A. M. Moran, J. Phys. Chem. Lett. 3, 2575-2581 (2012).

${ }^{11}$ S. Savikhin, T. Wells, P.-S. Song, and W. S. Struve, Biochemistry 32, 75127518 (1993)

${ }^{12}$ S. Mitra, Sample Preparation Techniques in Analytical Chemistry (John Wiley and sons, INC., 2003)
${ }^{13}$ J. M. Berg, J. L. Tymoczko, and L. Stryer, in Biochemistry, edited by S. Moran, G. L. Hadler, and P. Zimmerman (W H Freeman, 2002).

${ }^{14}$ R. Rippka, J. Deruelles, J. B. Waterbury, M. Herdman, and R. Y. Stanier, J. Gen. Microbiol. 111, 1-61 (1979).

${ }^{15}$ R. J. Porra, Photosynth. Res. 73, 149-156 (2002).

${ }^{16}$ A. Chauvet, N. Dashdorj, J. H. Golbeck, T. W. Johnson, and S. Savikhin, J. Phys. Chem. B 116(10), 3380-3386 (2012).

${ }^{17}$ C. Consani, M. Prémont-Schwarz, A. ElNahhas, C. Bressler, F. van Mourik, A. Cannizzo, and M. Chergui, Angew. Chem. 121, 7320-7323 (2009).

${ }^{18}$ J. Helbing, L. Bonacina, R. Pietri, J. Bredenbeck, P. Hamm, F. van Mourik, F. Chaussard, A. Gonzalez-Gonzalez, M. Chergui, C. Ramos-Alvarez, C. Ruiz, and J. López-Garriga, Biophys. J. 87, 1881-1891 (2004).

${ }^{19}$ A. Lisibach, E. Casartelli, and N. Schmid, paper presented at the ASME 2010 3rd Joint US-European Fluids Engineering Summer Meeting and 8th International Conference on Nanochannels, Microchannels, and Minichannels, Montreal, Quebec, Canada, 2010.

${ }^{20}$ A. P. G. M. Thielen and H. J. van Gorkom, Biochem. Biophys. Acta. 635(1), 111-120 (1981).

${ }^{21}$ S. Savikhin, W. Xu, P. Martinsson, P. R. Chitnis, and W. S. Struve, Biochemistry 40, 9282-9290 (2001).

${ }^{22}$ H. Sakurai, K. Inoue, T. Fujii, and P. Mathis, Photosynth. Res. 27, 65-71 (1991).

${ }^{23}$ G. Hastings, F. A. M. Kleinherenbrink, S. Lin, and R. Blankenship, Biochemistry 33, 3185-3192 (1994).

${ }^{24}$ K. Brettel and M. H. Vos, FEBS Lett. 447, 315-317 (1999).

${ }^{25}$ P. Jordan, P. Fromme, H. T. Witt, O. Klukas, W. Saenger, and N. Krauss, Nature (London) 411, 909-917 (2001).

${ }^{26}$ F. A. Lima, C. J. Milne, D. C. V. Amarasinghe, M. H. Rittmann-Frank, R. M. van der Veen, M. Reinhard, V.-T. Pham, S. Karlsson, S. L. Johnson, D. Grolimund, C. Borca, T. Huthwelker, M. Janousch, F. van Mourik, R. Abela, and M. Chergui, Rev. Sci. Instrum. 82, 063111 (2011) 